\title{
CoviD-19 The contributions of NHS healthcare workers who are shielding or working from home during COVID-19
}

\author{
Authors: Indrajit Chattopadhyay, ${ }^{A}$ Glesni Davies ${ }^{B}$ and Vedamurthy Adhiyaman ${ }^{A}$
}

During the COVID-19 pandemic, many healthcare staff and others who work for the NHS have been working from home (WFH) or shielding due to various health conditions, including pregnancy. While emphasis has been given to the support and wellbeing of those working at the frontline, little is known about the contribution of those who are working remotely. This online survey attempts to throw some light on how these healthcare workers have been contributing to the NHS while $\mathrm{WFH}$, the resources they may or may not have to undertake their remote duties, their perception of whether their contribution is valued at the workplace, and their views on whether the new ways of working would influence the manner in which they would work in the future.

KEYWORDS: COVID-19, working from home, shielding, healthcare workers, survey

DOI: $10.7861 /$ fhj.2020-0096

\section{Introduction}

The ongoing COVID-19 pandemic has seen people with various health conditions, including vulnerable frontline healthcare staff, being asked to shield or work from home., ${ }^{1,2}$ While many NHS workers with health conditions, including pregnancy, have been advised to stay at home following risk assessments at the workplace, many of these individuals have been trying to contribute to the NHS remotely, subject to the availability of access and resources to facilitate this. ${ }^{3,4}$ There is little systematic information on the range of activities undertaken by individuals who are working from home (WFH), or on how they feel about their contribution or how their current experience of working differently might influence how they may wish to work in the future.

\section{Aims}

The survey was undertaken to ascertain how the healthcare workers who are shielding or WFH have been contributing to the NHS, what resources were made available to them, their views

Authors: A consultant physician, Glan Clwyd Hospital, Rhyl, UK; ${ }^{B}$ specialty trainee, Glan Clwyd Hospital, Rhyl, UK on their contribution to the NHS, and whether they felt that they would change the manner in which they work in the future.

\section{Methodology}

The survey was undertaken using SurveyMonkey (www.surveymonkey. co.uk), a cloud-based online platform, over a period of 10 days in May 2020. The invitation to participate in the survey was sent out by emails to those staff in our Health Board in north Wales who were shielding or working from home and also disseminated through social media for healthcare professionals across the UK.

\section{Results}

We had 128 respondents, of whom $86.7 \%$ were medical, $5.5 \%$ were nursing staff, $4.7 \%$ were allied healthcare professionals and $3.1 \%$ were administrative staff. $95.3 \%$ were advised to shield or work from home due to health reasons (including pregnancy) and $4.7 \%$ due to having a vulnerable member in the family. The vast majority ( $97.7 \%$ ) felt that the decision for them to be shielded or to work from home had been justified.

$79 \%$ (99 of 128) were able to work from home, but out of these, 21 (21 of 99) did not have adequate resources to enable them to work to their optimal extent. $14 \%$ stated that they were willing to work if they had access to the appropriate resources. The remaining $7 \%$ were not working and either did not have access to resources for WFH or preferred not to use them. Of those who were able to $\mathrm{WFH}$, the nature of the duties executed from home included carrying out telephone clinics, providing clinical advice, participating in meetings, doing rotas, carrying out virtual triage, undertaking leadership roles, planning departmental activities, preparing educational materials and delivering online training, carrying out quality improvement projects and research, online prescribing and offering pastoral support (Fig 1).

The responses to the survey questions that had 'yes/no/don't know or unsure' variables are illustrated in Table 1. Nearly $48 \%$ felt that they were letting the NHS down by not being able to go to work, though $57.8 \%$ felt that they had the satisfaction that they were still able to contribute to the NHS while working from home. While nearly $57 \%$ of those working felt that their work was being valued by others, $16 \%$ did not feel the same way and the rest $(27.4 \%)$ did not know whether or not their contribution was being appreciated. $43 \%$ felt that they would change the way they would work in the future though $28 \%$ did not wish to change their working practices. Examples of different ways of working that 


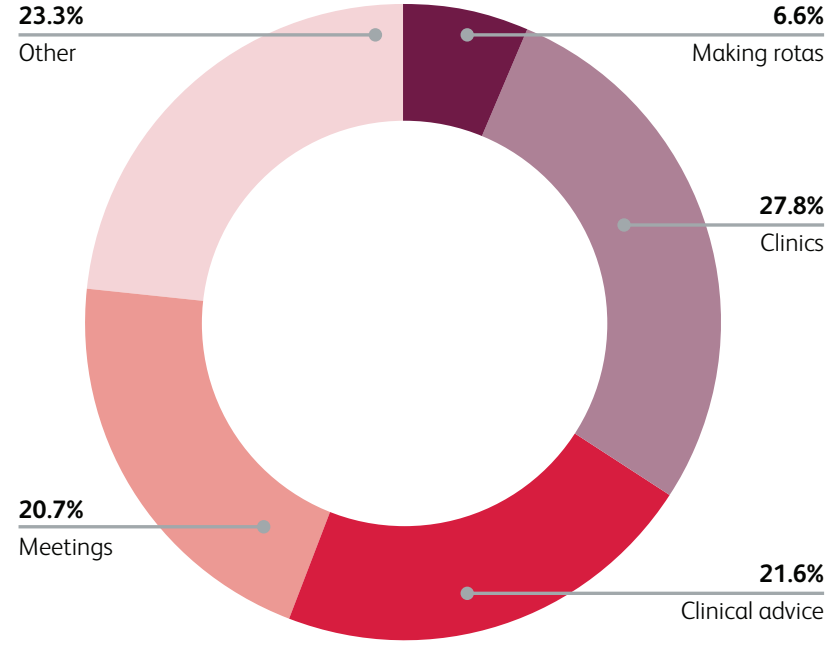

Fig 1. Types of remote work undertaken by those working from home.

might be used more frequently in the future included virtual clinics, remote working, virtual meetings and remote ways to undertake continuing professional development.

\section{Discussion}

The respondents were predominantly doctors (87\%). Given the manner in which the survey was disseminated and judging by the responses, it is likely that the respondents were from a wide cross-section across the UK. Even though the majority were able to do some work from home, 21 of the 128 respondents did not have all the resources needed and 18 did not have any resources at all, indicating that the full potential of the NHS workforce staying at home have not been utilised. The survey did not ascertain whether those who obtained the resources to work remotely had these provided readily by the employer or whether personal endeavours were required to achieve this. Those WFH have been undertaking a wide variety of activities, sometimes in combination, including remote clinics, triage work, providing clinical advice, undertaking management, leadership, administrative and pastoral roles, quality improvement and other educational activities to help the specialty, department or the wider workplace.
Nearly half the respondents ( $48 \%$ ) felt guilt that they were unable to go to work physically and 29 respondents $(22.7 \%)$ did not feel satisfied that they were able to contribute significantly to the NHS due to the constraints of being at home. Unfortunately, 49 out of 113 respondents $(43.4 \%)$ felt that their remote contribution to the NHS had either not been valued or that they were uncertain if their work was being acknowledged. This demonstrates that a significant proportion of those who are WFH may feel undervalued and workplace colleagues and managers should do more to proactively acknowledge their contribution.

Since the start of the pandemic there has been a lot of focus on supporting the wellbeing of those clinicians on the frontline., 5 It is important that we do not overlook the wellbeing of those WFH, whose feelings of guilt and of feeling undervalued may be having a negative impact on their wellbeing, particularly with the loss of social bonds with colleagues. Although we did not ask the participants specifically regarding childcare, many who are WFH may also be facing the additional challenge of combining this with caring for dependents, which could contribute to stress and have an adverse effect on their wellbeing. ${ }^{7}$ It is therefore crucial that workplace supervisors regularly communicate and support these individuals WFH.

Considering that many of those WFH have had more experience of working differently using remote technology, it is not surprising that nearly half of them ( $43 \%$ ) felt that they would continue to work differently in the future, including increased use of virtual means to undertake clinics, consultations and meetings.

We were unable to ascertain the response rate of the survey; however, obtaining 128 responses over a span of 10 days was encouraging. The respondents were skewed towards being doctors, though it would have been better to obtain a higher proportion of responses from non-medical NHS staff staying at home. Our survey was not designed to assess the intensity of work and it was not possible to validate the authenticity of the responses. Nevertheless, the survey did give an overview of the range of activities undertaken by the staff staying at home during these unprecedented times.

\section{Conclusion}

Though the majority of those surveyed (79\%) were working while staying at home, the full potential of this workforce had not been utilised due to inadequate availability or provision of resources.

Table 1. Views of those shielding or working from home in response to some survey questions

\begin{tabular}{|c|c|c|c|}
\hline \multirow[t]{2}{*}{ Survey question } & \multicolumn{3}{|c|}{ Response } \\
\hline & Yes & No & Don't know/unsure \\
\hline Do you feel that you are letting the NHS down by not being able to go to work? & $\begin{array}{l}61 / 128 \\
(47.7 \%)\end{array}$ & $\begin{array}{l}55 / 128 \\
(43 \%)\end{array}$ & $\begin{array}{l}12 / 128 \\
(9.3 \%)\end{array}$ \\
\hline $\begin{array}{l}\text { Do you have the satisfaction that you are able to contribute to the NHS given the } \\
\text { constraints you are facing due to shielding or being at home? }\end{array}$ & $\begin{array}{l}74 / 128 \\
(57.8 \%)\end{array}$ & $\begin{array}{l}29 / 128 \\
(22.7 \%)\end{array}$ & $\begin{array}{l}25 / 128 \\
(19.5 \%)\end{array}$ \\
\hline Do you feel that your work is being valued by others? & $\begin{array}{l}64 / 113 \\
(56.6 \%)\end{array}$ & $\begin{array}{l}18 / 113 \\
(16 \%)\end{array}$ & $\begin{array}{l}31 / 113 \\
(27.4 \%)\end{array}$ \\
\hline Would you change the way you work in the future? & $\begin{array}{l}55 / 128 \\
(43 \%)\end{array}$ & $\begin{array}{l}36 / 128 \\
(28 \%)\end{array}$ & $\begin{array}{l}37 / 128 \\
(29 \%)\end{array}$ \\
\hline
\end{tabular}


Despite remote working and some satisfaction that they were still able to contribute to the NHS, nearly half of the respondents felt that they were letting the NHS down by not being able to go to work. Given the wide variety of work that those WFH are undertaking during the pandemic, workplace colleagues and managers should do more so that that these individuals feel acknowledged and valued for their contribution to the NHS at these challenging times.

\section{References}

1 Public Health England. Guidance on shielding and protecting people who are clinically extremely vulnerable from COVID-19. PHE, 2020. Available from www.gov.uk/government/publications/ guidance-on-shielding-and-protecting-extremely-vulnerablepersons-from-covid-19/guidance-on-shielding-and-protectingextremely-vulnerable-persons-from-covid-19 [Accessed 28 May 2020].

2 Royal College of Obstetricians and Gynaecologists. COVID-19 virus infection and pregnancy. Occupational health advice for employers and pregnant women during the COVID-19 pandemic. Version 3.1. RCOG, 2020.
3 NHS Employers. Enabling and supporting staff to work from home. NHS Employers, 2020. Available from www.nhsemployers.org/ covid19/health-safety-and-wellbeing/enabling-and-supportingstaff-to-work-from-home [Accessed 28 May 2020].

4 Hayes $B$. Working from home in medicine during coronavirus: What equipment do you need to get started and what can you do to help from home? Future Health ] 2020;7:163-4.

5 Greenberg N, Docherty Mm et al. Managing mental health challenges faced by healthcare workers during covid-19 pandemic. BMJ 2020;368:m1211.

6 Greenberg N, Tracy D. What healthcare leaders need to do to protect the psychological well-being of frontline staff in the COVID-19 pandemic. BMJ Leader 2020, in press (doi: 10.1136/leader-2020000273).

7 Bansal P, Bingemann T et al. Clinician wellness during the COVID-19 pandemic: extraordinary times and unusual challenges for the allergist/ immunologist. J Allergy Clin Immunol Pract 2020;8:1781-90.

Address for correspondence: Dr Indrajit Chattopadhyay, Department of Geriatric Medicine, Glan Clwyd Hospital, Rhyl, LL18 5UJ, UK.

Email: indrajit.chatterjee@wales.nhs.uk 